Dermatology 2011;222:22-23

DOI: $\underline{10.1159 / 000317074}$

\section{Mobile Phones: A Role in Teaching Dermatology?}

\section{Alessandro Giunta, Alessandro Di Stefani, Sergio Chimenti}

Department of Dermatology, University of Rome Tor Vergata, Rome, Italy

\section{Key Words}

Mobile phones $\cdot$ Blended learning $\cdot$ Learning methods

Medical school curricula have been markedly revolutionized, evolving from the traditional plenary-lecture-based model to small-attendant-symposium-based methods or to a practical, patient-based approach. Recently, electronic learning has been proposed as a major tool for teaching medicine, and a number of disciplines launched educational programs via the Web. Most of the changes introduced so far focalized on the development of computer tools as complements to traditional teaching methods. In this model, called 'blended learning', online resources represent a source of support material for the traditional attendancebased teaching [1]. Blended learning has been demonstrated to facilitate classroom management, especially for large classes [2], to improve self-confidence and overall satisfaction with the learning experience $[3,4]$, to enhance students' expertise acquisition [5, 6] and possibly to reduce student withdrawals and absenteeism [7]. However, the potentiality of a number of new technologies, including the mobile-phone-based communication by SMSs (short message service) or MMSs (multimedia message service), have been underestimated so far.

The aim of our study was to evaluate the feasibility and the educative value of an SMS/MMS-based blended-learning model as compared to the traditional attendance-based one. A total of 212 students attending the course of dermatology at the Medical School of the University of Rome Tor Vergata had been randomly assigned at a 1:3 ratio to two different groups, namely A and B, of 53 and 159 students, respectively. Both groups attended the tradi- tional face-to-face course, composed of $25 \mathrm{~h}$ devoted to lectures and of a 2 -week clinical training period. Throughout the course, all students had a free and unrestricted access to printable extra teaching material via the Web (http://www.dermatologica.it). Group A students attended also a mobile-phone-based integrative course and received, during the 10 -week course of dermatology, a total of 80 SMSs of multiple-choice questions, MMSs with questions on clinical images and SMSs with commented solutions. The students' telephone numbers were anonymous. At the end of the course, all students were evaluated by a 60 -item multiple-choice anonymous questionnaire. All students were well informed that the results of the questionnaire would not have any impact on the outcome of the final examination. While all group A students filled in the final questionnaire, 25 group B students (15.72\%) withdrew from the course. The marks of the questionnaires are summarized in figure 1. In group A, the mean number of correctly answered questions was 47.98 (79.96\%), and 50/53 (94.34\%) students virtually moved up. Instead, the number of correct answers in group B was significantly smaller $(29.06,48.43 \%$; $p<0.001)$, and only $30 / 134(22.39 \%)$ students passed the virtual examination. The results and the statistical analysis are summarized in table 1.

Today's dermatology teachers are facing different challenges than their predecessors. Finding time to teach 'new' fields, including immunology or dermatoscopy, is difficult when medical school curricula have to cover conventional topics. In this view, e-learning can be successfully used to improve the effectiveness of educational interventions. However, the implementation of these platforms is expensive and highly demanding of teaching staff, especially in terms of organization of the course [8], clear definition of its rules and making of the learning apparatus, which have to include exercises, texts and tutorial and self-assessment tools. Recent initiatives utilizing free software and computer networks shared by several medical schools may be useful in this sense but these facilities are not widely available and require a difficult-toreach consensus on learning objectives and teaching programs between academies. We propose an alternative approach that utilizes common-life communication instruments such as mobile phones as teaching platforms. The major advantages are that this widely available everyday-life technology is low-cost and does not

Table 1. Comparison of the results between the students using blended learning and those attending the traditional course

\begin{tabular}{llll}
\hline & Correct answers, $\%$ & Errors, $\mathrm{n}$ & Marks, $\mathrm{n} / 30$ \\
\hline Mean of differences & 30.283 & -18.1698 & 9.08491 \\
95\% confidence interval of mean & $24.5929-35.9731$ & -21.5837 to -14.7559 & $7.37794-10.7919$ \\
Standard deviation of differences & 20.639 & 12.3829 & 6.19145 \\
Probability & $1.00676 \times 10^{-14}$ & $1.03835 \times 10^{-14}$ & $1.03835 \times 10^{-14}$ \\
\hline
\end{tabular}

All differences are statistically significant (software Statistics, Blackwell Scientific Publications, version W1.59).

\section{KARGER}

Fax +4161306 1234 E-Mail karger@karger.ch www.karger.com
Sergio Chimenti, MD

Department of Dermatology, University of Rome Tor Vergata

Viale Oxford, 81, IT-00133 Rome (Italy)

Tel. +39 062090 2743, Fax +39 0620902742

E-Mail chimenti@dermatologica.it 


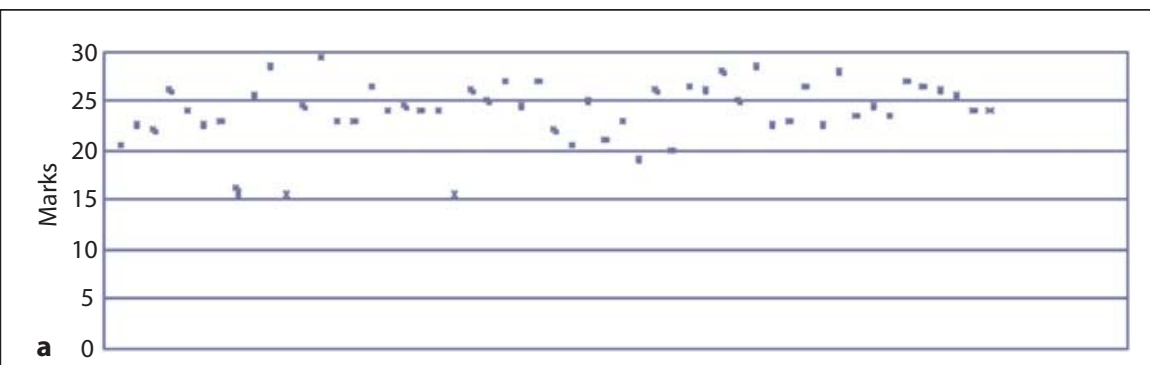

Fig. 1. Marks of group A (a) and B (b) students expressed as $1 / 30$, as used in Italian Universities. c Comparison between the marks of group A and B students (expressed as 1/30).
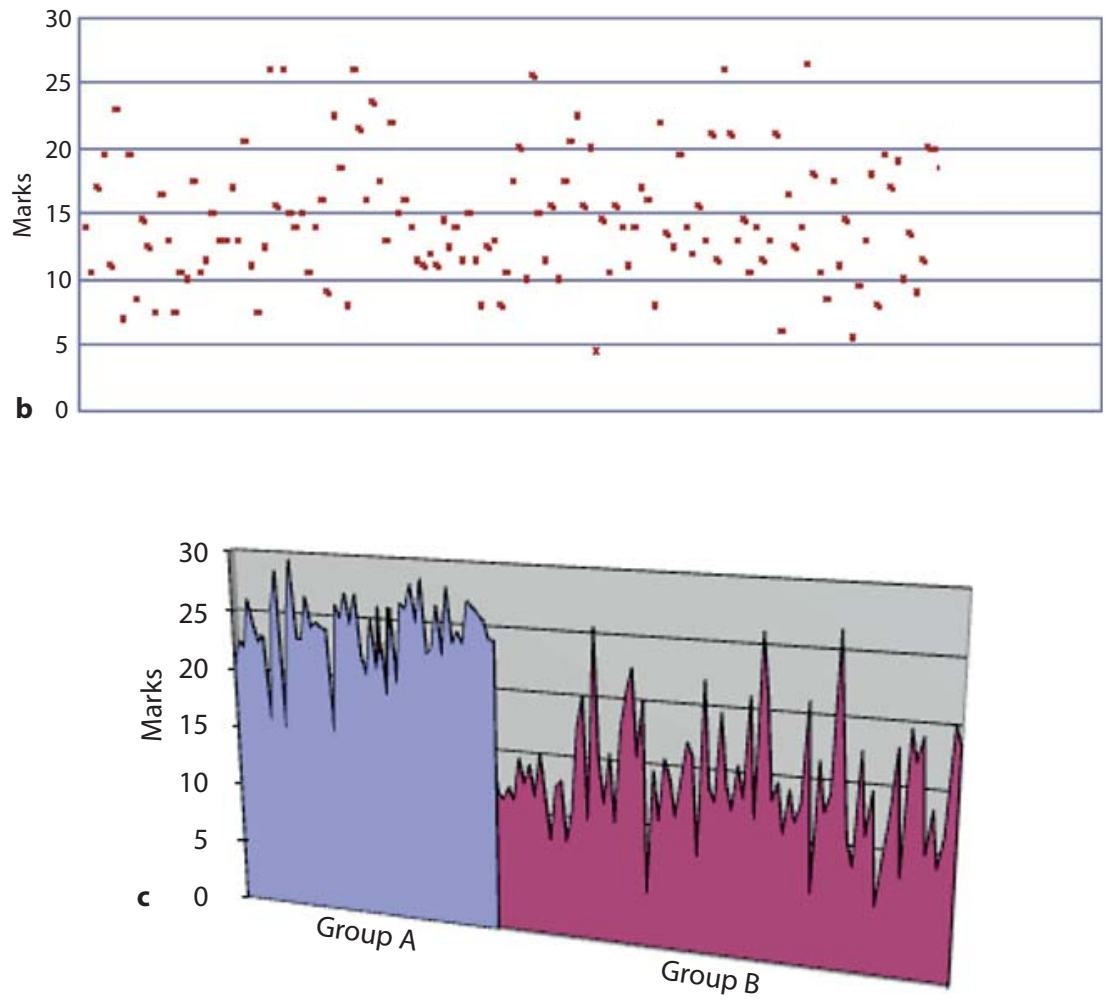

require training. Furthermore, the possibility to send both text and images by this technology seems perfectly tailored to dermatology. The significant improvement in academic performance and the reduction of withdrawals observed in our experience demonstrate that our e-learning model can successfully be used to improve the effectiveness of educational interventions.

\section{Acknowledgements}

The authors would like to express their gratitude to the students of the School of Medicine of the University of Rome Tor Vergata for their availability and collaboration.

\section{References}

1 Ashwell KW, Halasz P: An Acrobat-based program for gross anatomy revision. Med Educ 2004;38:1185-1186.
Papo W: Integration of educational media in higher education large classes. Educ Media Int 2001;38:95-99.

-3 Saunders G, Klemming F: Integrating technology into a traditional learning environment: reasons for and risks of success. Active Learning Higher Educ 2003;1:74-86.

4 Byers C: Interactive assessment: an approach to enhance teaching and learning. J Interactive Learning Res 2001;12:359-374.

5 Kendall M: Teaching online to campus-based students. Educ Inf 2001; 19:325-346.

6 Novitzki JE: Asynchronous learning tools in the traditional classroom: a preliminary study on their effect. Int Acad Inf Manag Annu Conf, Brisbane, 2002.

7 Sorg S, Juge F, Bledsoe R: Institutional change through a web-enhanced course model. Fla Educ Technol Conf, Orlando, 2000. http://distrib.ucf. edu/dlucf/present.htm.

8 Singh H: Building effective blended learning programmes. Educ Technol 2003;43:51-54 